\title{
Photosynthetic response of the floating-leaved macrophyte Nymphoides peltata to a temporary terrestrial habitat and its implications for ecological recovery of Lakeside zones
}

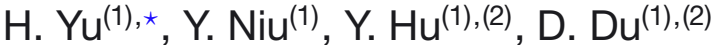 \\ Received September 12, 2013 \\ Revised November 26, 2013 \\ Accepted December 3, 2013
}

Key-words: Nymphoides peltata, gas exchange, water-use efficiency, acclimation, lakeside zone restoration

\section{ABSTRACT}

For the ecological recovery of lakeside zones in shallow eutrophic lakes, choosing suitable aquatic macrophytes which could adapt to the temporary terrestrial habitat due to water level change is very important. In the present study, an experimental approach was carried out to explore the photosynthetic response of the typical floating-leaved aquatic plant Nymphoides peltata ( $N$. peltata) to varying environmental factors. $N$. peltata grown under aquatic and terrestrial habitats showed similar photosynthesis-irradiance response patterns. The investigation of diurnal changes in gas exchange revealed that the net photosynthetic rate $\left(P_{N}\right)$ and water-use efficiency (WUE) of the $N$. peltata grown in the terrestrial habitat were $68 \%$ and $94 \%$ higher, respectively, than those in the aquatic habitat at nine in the morning. N. peltata grown in the terrestrial habitat had approximately $51 \%$ less stomatal density and a $77 \%$ smaller stomatal aperture area compared with those grown in aquatic habitats. The above results indicated that $N$. peltata could be well-acclimated to the terrestrial habitat by developing a series of photosynthetic acclimation features. Our study may provide an important reference for restoration in lakeside zones of shallow eutrophic lakes.

\section{RÉSUMÉ}

Réponse photosynthétique d'un macrophyte à feuilles flottantes Nymphoides peltata à un habitat terrestre temporaire et ses implications pour la restauration écologique de zones littorales lacustres

\section{Mots-clés :}

Nymphoides

peltata, échange de gaz,

efficacité

d'utilisation

de l'eau
Pour la restauration écologique de la zone littorale dans les lacs eutrophes peu profonds, le choix des macrophytes aquatiques appropriés qui pourraient s'adapter à l'habitat terrestre temporaire dû aux changements du niveau de l'eau est très important. Dans la présente étude, une approche expérimentale a été menée pour étudier la réponse photosynthétique d'une plante aquatique à feuilles flottantes typique Nymphoides peltata ( $N$. peltata) à des facteurs environnementaux changeants. Des $N$. peltata cultivés dans des habitats aquatiques et terrestres ont montré des schémas «photosynthèse-éclairement » de réponse similaires. L'étude des variations diurnes des échanges gazeux a révélé que le taux de photosynthèse

(1) Research Center For Lake Ecology and Environment, Chinese Research Academy of Environmental Sciences, Beijing 100012, P.R. China

(2) Faculty of Resources and Environment, Hubei University, Wuhan 430062, P.R. China

* Corresponding author: yuhui@craes.org.cn 
acclimatation, restauration de zone littorale nette (PN) et l'efficacité d'utilisation de l'eau (EUE) des $N$. peltata cultivés dans I'habitat terrestre étaient de $68 \%$ et $94 \%$ plus élevés, respectivement, que ceux de l'habitat aquatique à neuf heures du matin. $N$. peltata cultivés dans I'habitat terrestre avaient une densité stomatique environ $51 \%$ inférieure et une surface d'ouverture des stomates inférieure de $77 \%$ par rapport à ceux qui sont cultivés dans les habitats aquatiques. Les résultats ci-dessus montrent que $N$. peltata pourrait être bien acclimaté à I'habitat terrestre en développant une série de caractéristiques d'acclimatation photosynthétiques. Notre étude pourrait fournir une référence importante pour la restauration dans la zone littorale de lacs eutrophes peu profonds.

\section{INTRODUCTION}

Lakeside zones are transitional areas between the land and water where the water level changes dramatically. Many problems exist in lakeside zones such as narrow lakeshore areas, low coverage of aquatic vegetation, dramatic changes in the water level, and so on. In the lakeside zones, aquatic macrophytes determine the effectiveness of the well-known services of wetlands to society, such as the sustainable production of food, recreational opportunities, and water purification by retention of pollutants and sediments (Engelhardt et al., 2001). In the lakeside zone of shallow lakes, a variety of environmental factors interact to affect the productivity, distribution and species composition of aquatic macrophyte communities, among which are water depth, light, sediment composition (Barko et al., 1986) and anthropogenic disturbance (Nishihiro et al., 2006). Previous studies on the adaptation of aquatic plants to water level fluctuations in the lakeside zone have mainly focused on how these plants adapt to submersed growth, which includes leaf, root and shoot morphology, as well as anatomic changes (Robe et al., 1998; Lynn et al., 2003; Mommer et al., 2005). A few studies have been conducted regarding adaptations that allow floating-leaved or submersed plants to withstand terrestrial habitats due to water level decline and other environmental factors. For example, previous studies indicated that floating-leaved plants, such as $N$. peltata, could adapt well to temporary terrestrial habitats due to high phenotypic and physiological flexibility, including longer leaf longevity (Tsuchiya, 1988), a higher root biomass allocation and a decrease in the lacunal system volume, as well as higher water-use efficiency (WUE) (Li et al., 2010, 2011). Heterophylly is also thought to be an important adaptive phenotypic plasticity in aquatic plants (Wells et al., 2000). However, little is known about the photosynthetic acclimation of plants during water level changes.

Nymphoides peltata, a typical floating-leaved aquatic plant in lakeside zones, is native to Eurasia and widely distributed in the temperate regions of the northern hemisphere. In China, $N$. peltata grows in the lakeside zones of small to large lakes distributed across the Yangtze River Basin (such as Lakes Dongting, Poyang and Taihu), particularly in transitional areas from the sublittoral zone to open water. The presence of $N$. peltata is an indication of a dynamic environment with water movements caused by wind, currents or/and tidal oscillations. It has been found most frequently at water depths from 1 to $1.5 \mathrm{~m}$ and the average degree of coverage increases with depth (Van der et al., 1979). N. peltata shows a higher plasticity in life form, depending on the developmental stage and environmental conditions (Tsuchiya, 1988). Depending on the slope and depth to base flow, N. peltata may be exposed to continuous flooding, periodic flooding and periodic drought. It can also grow in damp marshes. Some may even develop into small, terrestrial plants on temporarily dried sediments (Tsuchiya, 1991). We hypothesized that $N$. peltata might develop numerous photosynthetic acclimation features to help the plant cope with temporary terrestrial habitats. To this end, an experimental approach was employed to study the photosynthetic responses of $N$. peltata to temporary terrestrial habitats by comparing physiological, morphological and anatomical traits under aquatic and terrestrial growth conditions. We also evaluated the potential for recovery of lakeshore vegetation by assessing $N$. peltata's adaptive ability in terrestrial habitats. 


\section{MATERIALS AND METHODS}

\section{$>$ CULTURE OF PLANTS}

Nymphoides peltata (Gmel.) O. Kuntze (Menyanthaceae) was chosen for this research because of its potential adaption ability. About forty short shoots (rootstocks) of Nymphoides peltata of uniform size $(6.5-7.7 \mathrm{~g})$ with intact roots but without leaves were collected from the west lakeside of Lake Taihu. The shoots were then transplanted on March 9, 2010, and placed in ten $0.5 \mathrm{~m}^{3}(1.0 \mathrm{~m}$ (length) $\times 0.5 \mathrm{~m}$ (width) $\times 1.0 \mathrm{~m}$ (depth)) plastic containers filled with quartz and sandy soil (about $10 \mathrm{~cm}$ ). Ten plants were used in each of the treatments. In the sediment, total nitrogen, total phosphorus and the percentage of organic matter were $2.94 \mathrm{mg} \cdot \mathrm{g}^{-1}$. dry weight, $0.128 \mathrm{mg} \cdot \mathrm{g}^{-1}$. dry weight and $12.85 \%$, respectively. The water depth of the terrestrial and aquatic treatments were $0 \mathrm{~cm}$ (soil saturated with water) and $50 \mathrm{~cm}$ (above soil level), respectively. During the experiment, lake water was added to the plastic containers to maintain water level and soil saturation. The TN, TP, $\mathrm{NH}_{4}^{+}-\mathrm{N}$ and $\mathrm{NO}_{3}-\mathrm{N}$ of the lake water were $3.06 \pm 0.66 \mathrm{mg} \cdot \mathrm{L}^{-1}, 0.15 \pm 0.08 \mathrm{mg} \cdot \mathrm{L}^{-1}, 0.90 \pm 0.39 \mathrm{mg} \cdot \mathrm{L}^{-1}$ and $0.35 \pm 0.12 \mathrm{mg} \cdot \mathrm{L}^{-1}$, respectively.

\section{> GAS EXCHANGE MEASUREMENT}

After plant culture in aquatic and terrestrial habitats for $60 \mathrm{~d}$, gas exchange measurements were carried out on mature, fully expanded leaves with a LI-6400 portable system (LiCor, Lincoln, Nebraska, USA). Photon flux density (PPFD) curves of the net photosynthesis $\left(P_{\mathrm{N}}\right)$ were examined in air $\left[340 \mu \mathrm{mol}\left(\mathrm{CO}_{2}\right) \mathrm{mol}^{-1}\right]$ at $30{ }^{\circ} \mathrm{C}$ at $1600,1400,1200,1000,800,600$, $400,200,150,75,50$ and $25 \mu \mathrm{mol} \cdot \mathrm{m}^{-2} \cdot \mathrm{s}^{-1}$ irradiance. Ten leaves from ten different plants were selected, i.e., ten replicates were performed. The chosen leaves were inserted with the abaxial leaf side upwards (to face the light). During the measurements, the air humidity in the sample chamber was $66 \%-77 \%$.

In order to understand Nymphoides peltata's photosynthetic response to various photosynthetic photon flux densities in both terrestrial and aquatic conditions, photosynthesis measurements were carried out on a clear day in June 2010 between 7:00 and 17:00 on fully expanded leaves at two-hour intervals. During the measurements, the PPFD varied from 269.1 to $1754.1 \mu \mathrm{mol} \cdot \mathrm{m}^{-2} \cdot \mathrm{s}^{-1}$ and air temperature varied from 29.0 to $45.2{ }^{\circ} \mathrm{C}$. The PPFD, air temperature $(T \mathrm{a}), P_{\mathrm{N}}$, transpiration rate $(E)$ and stomatal conductance $\left(g_{\mathrm{s}}\right)$ were measured with the LI-6400 portable photosynthesis system. WUE was calculated as $P_{\mathrm{N}} / E$. Ten replicates were performed at each time point. These data were also employed to explore the relationships between temperature, irradiance and photosynthetic parameters $\left(P_{\mathrm{N}}, g_{\mathrm{s}}, \mathrm{E}\right.$ and WUE).

\section{> STOMATAL DENSITY AND PORE AREA MEASUREMENT}

Three fresh leaves (10 $\mathrm{mm}$ around the petiole) of each plant were randomly selected for stomatal density determination and stomatal aperture area measurements at 9:00 am on the day of measurement. The stomata were observed using a scanning electron microscope (SEM) (Stereosan 420, Leica Cambridge Instruments). Standard preparation methods for the SEM were used (Morris et al., 1997). Stomatal density was calculated per $\mathrm{mm}^{2}$. The stomatal pore area was analyzed using image-analysis software (NIH Image, version 1.56), which converted the SEM photographs to a bitmap image and then calculated stomatal pore area.

\section{> DATA ANALYSIS}

The mean and standard deviation values were calculated for each treatment. All parameters between the two treatments were compared by one-way ANOVA using the SPSS statistical package (version 17.0, SPSS, Chicago, IL, USA). 


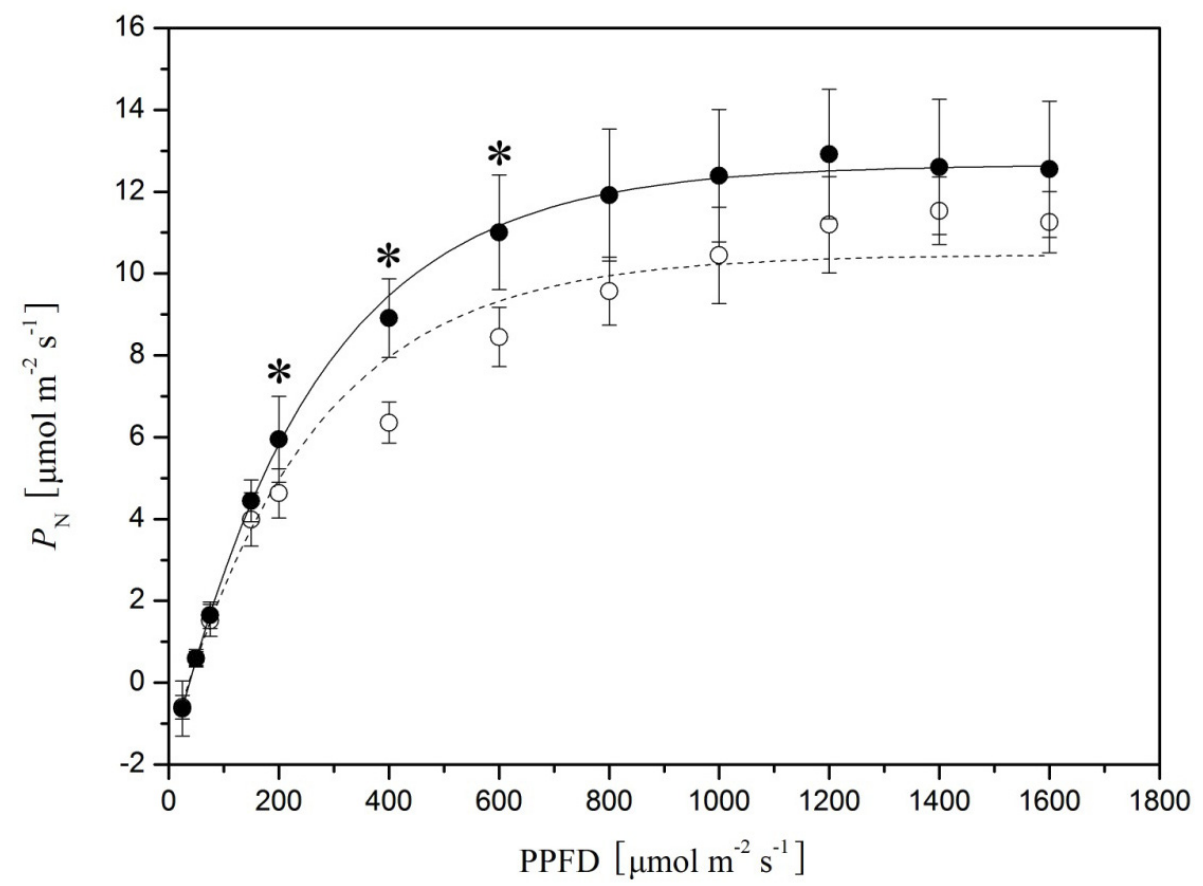

Figure 1

Irradiance $(P P F D)$ response curves of net photosynthetic rate $\left(P_{\mathrm{N}}\right)($ Mean $\pm S E, n=10)$ of $N$. peltata grown under aquatic ( $\bullet$ ) and terrestrial (०) conditions ( ${ }^{*} P<0.05$; $\bullet$ and $\circ$ measured, - and - - calculated by equation (1)).

The net photosynthetic rate of leaf $\left(P_{\mathrm{N}}\right)$ response to photosynthetic photon flux density (PPFD) was calculated from Webb's equation (Webb et al., 1974) as follows:

$$
P_{\mathrm{N}}=P_{\mathrm{Nmax}}\left[1-\exp \left(-\alpha \times \mathrm{PPFD} / P_{\mathrm{Nmax}}\right]\right.
$$

Where $P_{\mathrm{Nmax}}$ is the maximum value of the net photosynthetic rate, and $\alpha$ is the photosynthetic efficiency.

\section{RESULTS}

$N$. peltata grown under aquatic and terrestrial habitats showed similar photosynthesisirradiance response patterns (Figure 1). When irradiance was below $200 \mu \mathrm{mol} \cdot \mathrm{m}^{-2} \cdot \mathrm{s}^{-1}$, the $P_{\mathrm{N}}$ of $N$. peltata grown under aquatic and terrestrial habitats increased linearly with irradiance, and no significant difference between them was observed. $N$ peltata grown under the aquatic habitat exhibited a higher $P_{N}$ than that under the terrestrial habitat when irradiance ranged from 200 to $600 \mu \mathrm{mol} \cdot \mathrm{m}^{-2} \cdot \mathrm{s}^{-1}(p<0.05)$ (Figure 1). When irradiance ranged from 0 to $600 \mu \mathrm{mol} \cdot \mathrm{m}^{-2} \cdot \mathrm{s}^{-1}$, the $P_{\mathrm{N}}$ responded rapidly under both habitats, while the $P_{\mathrm{N}}$ varied slowly and gradually reached saturated status when irradiance was above $600 \mu \mathrm{mol} \cdot \mathrm{m}^{-2} \cdot \mathrm{s}^{-1}$ (Figure 1).

The photosynthetic parameters $\left(P_{\mathrm{Nmax}}, \mathrm{I}_{\mathrm{C}}, \mathrm{I}_{\mathrm{K}}\right.$ and $\alpha$ ) of $N$. peltata calculated by equation (1) under aquatic and terrestrial habitats are shown in Table I. All four parameters were similar between the two habitats; this indicated that the $N$. peltata can perform photosynthesis well and acclimate to temporary terrestrial habitats.

The diurnal $P_{\mathrm{N}}$ of $N$. peltata grown in the aquatic and terrestrial habitats reached a maximum at 13:00 (Figure 2a). At 7:00 and 9:00, the $P_{N}$ of $N$. peltata grown in the terrestrial habitat were significantly higher than those in the aquatic habitat ( $p=0.023$ and 0.013 , respectively). The $g_{\mathrm{s}}$ of $N$. peltata grown in the aquatic and terrestrial habitats showed similar patterns and the peak values occurred in the morning at 9:00 (Figure 2b). The N. peltata grown in the 


\section{Table I}

Photosynthetic parameters ( $P_{\mathrm{Nmax}}$, maximum net photosynthetic rate; $I_{\mathrm{C}}$, compensation irradiance; $I_{\mathrm{K}}$, light saturation parameter; $\alpha$, photosynthetic efficiency) of $N$. peltata grown under aquatic and terrestrial habitats calculated by equation (1).

\begin{tabular}{|l|c|c|}
\cline { 2 - 3 } \multicolumn{1}{c|}{} & Aquatic habitats & Terrestrial habitats \\
\hline $\boldsymbol{P}_{\text {Nmax }}\left(\boldsymbol{\mu} \mathbf{m o l} \cdot \mathbf{m}^{-\mathbf{2}} \cdot \mathbf{s}^{-1}\right)$ & 12.66 & 10.46 \\
\hline $\mathbf{I}_{\mathbf{C}}\left(\boldsymbol{\mu m o l} \cdot \mathbf{m}^{-2} \cdot \mathbf{s}^{-1}\right)$ & 37.41 & 36.43 \\
\hline $\mathbf{I}_{\mathbf{K}}\left(\boldsymbol{\mu} \mathbf{m o l} \cdot \mathbf{m}^{-2} \cdot \mathbf{s}^{-1}\right)$ & 219.98 & 212.65 \\
\hline $\boldsymbol{\alpha}$ & 0.048 & 0.041 \\
\hline
\end{tabular}

aquatic habitat had higher $g_{\mathrm{s}}$ at 7:00 and 9:00 $(p<0.01)$ than those of the terrestrial habitat. The $E$ of $N$. peltata grown in the aquatic habitat were higher than those of the terrestrial habitat at 7:00 $(p<0.001)$ and 9:00 $(p<0.01)$ (Figure 2c). The WUE of $N$. peltata grown in the terrestrial habitat was significantly higher than that in the aquatic habitat at 9:00 in the morning $(p<0.01)$, while the values were very similar at the other time points (Figure $2 d$ ).

The relationships between irradiance, temperature and other photosynthetic parameters $\left(P_{\mathrm{N}}, g_{\mathrm{s}}, E\right.$ and WUE) are shown in Figures 3 and 4. Basically, the WUE, $E$ and $P_{\mathrm{N}}$ of $N$. peltata grown under the two habitats increased with the PPFD and $T a$, while the $g_{\mathrm{s}}$ showed firstly an upward trend, then a downward trend.

No stomatal aperture exists on the abaxial side of the leaves, so only the data on the adaxial side are shown. The treatments significantly influenced the stomatal density and aperture area. The stomatal density of the terrestrial plants was $51 \%$ less than that of the aquatic plants $\left(319 \pm 65\right.$ and $649 \pm 92 \mathrm{~mm}^{-2}$, respectively), and the stomatal aperture area of the terrestrial plants was $77 \%$ smaller than that of the aquatic plants $\left(8.22 \pm 3.68\right.$ and $35.93 \pm 8.86 \mu \mathrm{m}^{2}$, respectively) (Figure 5, Table II).

\section{DISCUSSION}

The ability to modify physiological traits in response to temporary variation can increase fitness (Picotte et al., 2007). Our study demonstrated that $N$. peltata developed a series of photosynthetic acclimation features to help the plant cope with temporary terrestrial habitats, which included less stomatal density, a smaller stomatal aperture area, lower $E$ and $g_{\mathrm{s}}$, and high WUE. Meanwhile, since there was little difference in $P_{\mathrm{N}}$ between the terrestrial and aquatic habitats, $N$. peltata is one of the suitable aquatic macrophytes for recovery of lakeshore vegetation in shallow eutrophic lakes.

The significant reduction in $g_{\mathrm{s}}$ and $E$, as well as the increase in WUE of terrestrial $N$. peltata (Figure 2) are known as a feed-forward response, which may be associated with patchy stomatal closure for limited water loss. The significant reduction in $g_{\mathrm{s}}$ and Eallows the maintenance of high WUE (Saraswathi et al., 2008). High WUE, usually owing to stomatal limitations, has often been reported in seedlings (Calatayud et al., 2000; Saraswathi et al., 2008). Therefore, we speculated that the high WUE in N. peltata was possibly related to stomatal limitations.

Air temperature and irradiance can affect photosynthetic capacity. Generally, our study showed that the photosynthetic parameters of $N$. peltata exhibited similar variation trends with increasing air temperature and irradiance under the two different habitats (Figures 3 and 4). However, N. peltata showed several different photosynthetic traits under the two habitats. For example, when $T$ a was around $35^{\circ} \mathrm{C}, \mathrm{N}$. peltata growing under terrestrial habitats had higher WUE, lower $g_{s}$ and lower $E$ than those under aquatic habitats (Figure 4), which was also reflected by Figure 2 (9:00 am). By regulating these physiological activities, N. peltata could maintain its water balance and photosynthesis (Estill et al., 1991; Luquez et al., 1997). Thus, $N$ peltata growing under terrestrial conditions could acclimate to temporarily stressed environments. However, since the diurnal trends of temperature and light were similar, the effect of them cannot be separated completely in our study. The independent effects of temperature and light need further study. 


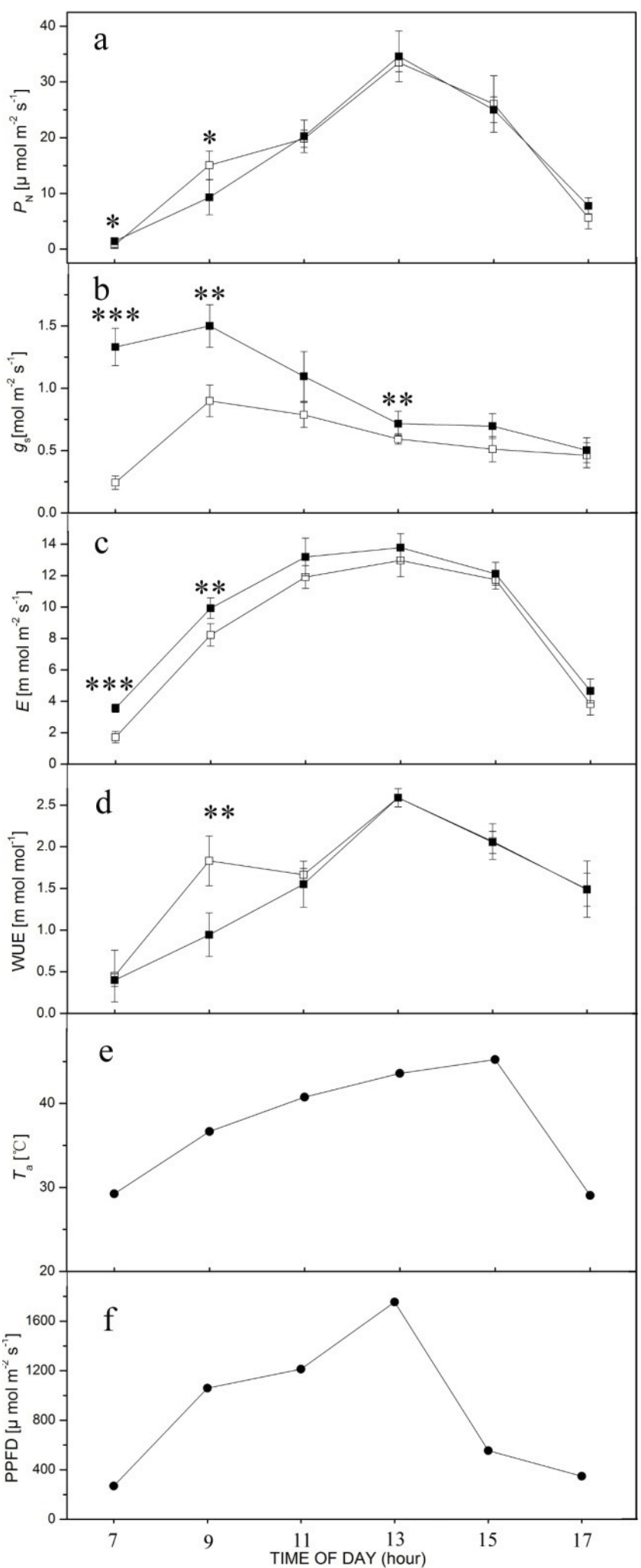

Figure 2

Diurnal course of photosynthetic rate $\left(P_{\mathrm{N}}\right)(a)$, stomatal conductance $\left(g_{s}\right)(b)$, transpiration rate $(E)(c)$ and water use efficiency (WUE) (d) (Mean $\pm S E, n=10)$ of $N$. peltata grown under aquatic (• and - - $)$ ) and terrestrial (o and -) conditions, and air temperature, $\mathrm{Ta}$ (e), average incident photosynthetic photon flux density, PPFD (f), during the experiment $\left({ }^{*} P<0.05,{ }^{* *} P<0.01,{ }^{* * *} P<0.001\right)$. 
H. Yu et al.: Knowl. Managt. Aquatic Ecosyst. (2014) 412, 08

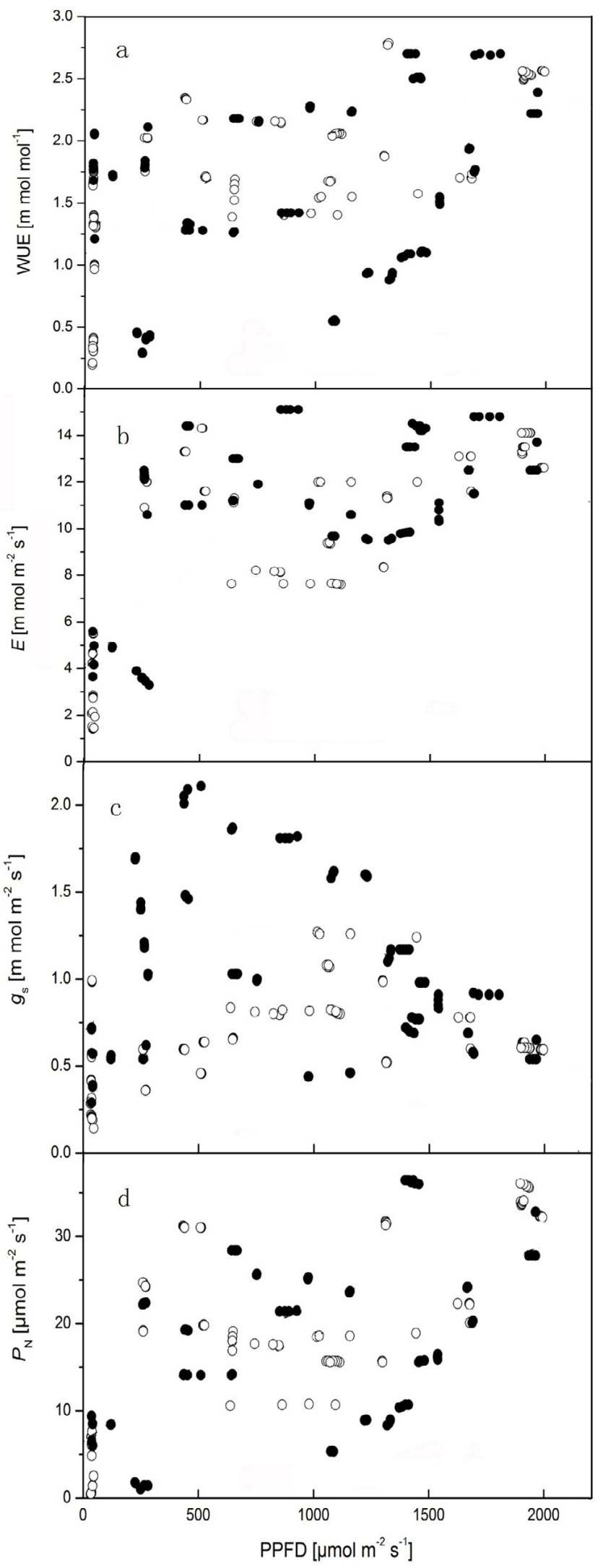

Figure 3

Relationship between PPFD and $P_{\mathrm{N}}, g_{\mathrm{s}}, E$ and WUE. (o: Under terrestrial culture, and $\bullet$ : Under aquatic culture). 
H. Yu et al.: Knowl. Managt. Aquatic Ecosyst. (2014) 412, 08

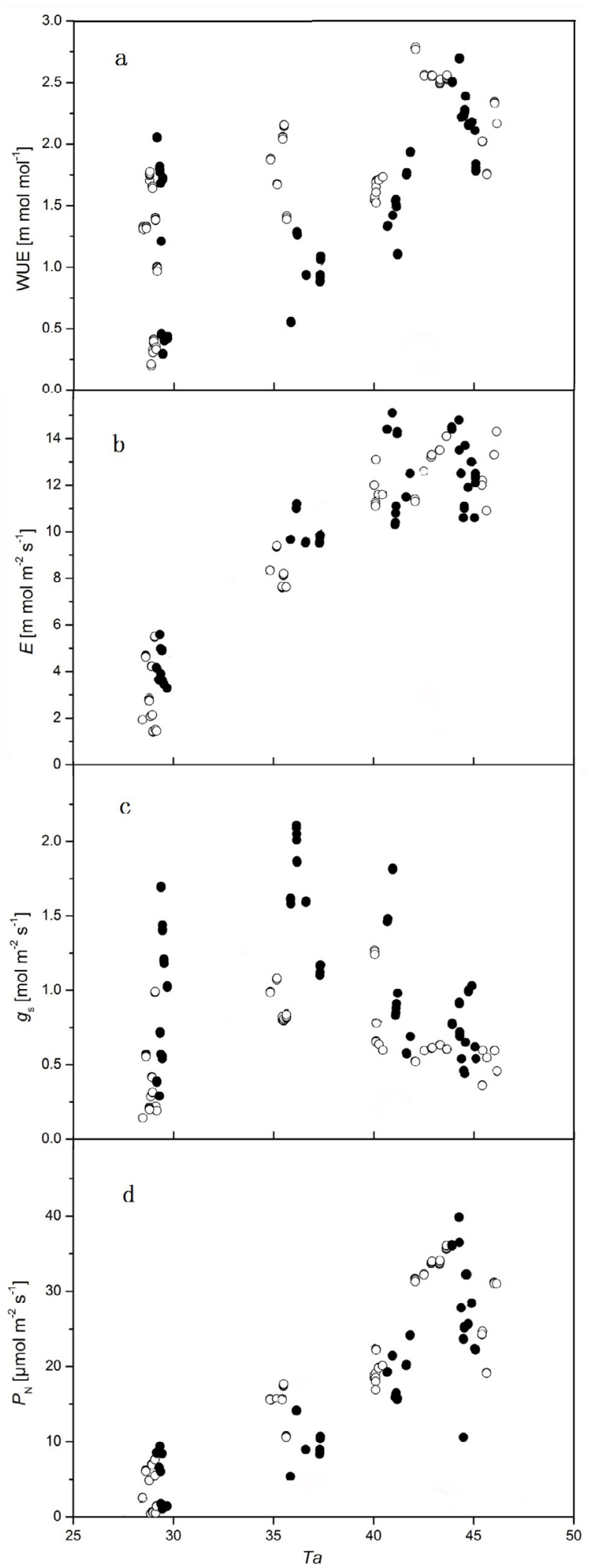

Figure 4

Relationship between $T a$ and $P_{\mathrm{N}}, g_{\mathrm{s}}$, Eand WUE (o: Under terrestrial culture, and $\bullet$ : Under aquatic culture). 


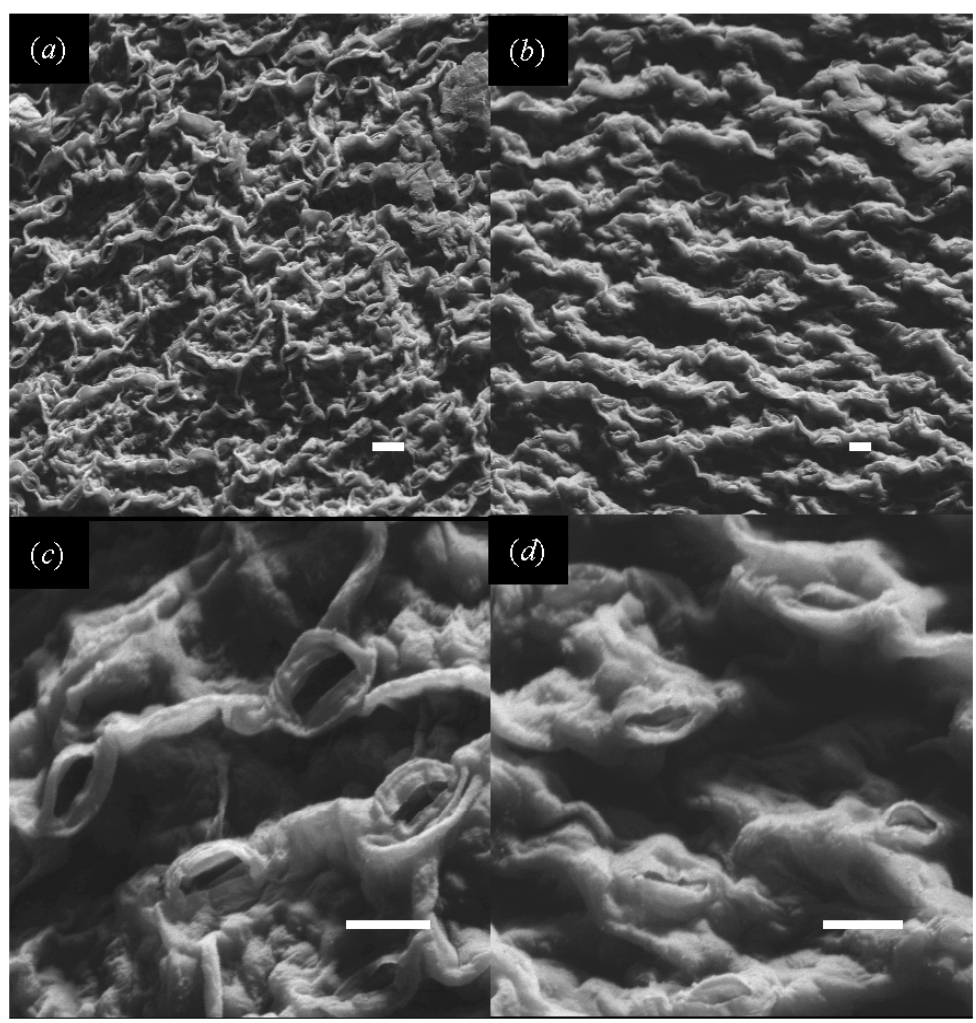

\section{Figure 5}

SEM photographs of the adaxial surface $(1 \mathrm{~cm}$ around petiole) of a typical youngest mature leaf grown in aquatic and terrestrial conditions. (a) and (b) showing stomatal density Magnification $\times 500$, scale bar $0.01 \mathrm{~mm}$; (c) and (d) showing stomatal aperture area grown under aquatic and terrestrial condition respectively, Magnification $\times 2000$, scale bar $0.01 \mathrm{~mm}$.

\section{Table II}

Results of the independent sample t-test on the stomatal density and stomatal aperture area of $N$. peltata grown in aquatic and terrestrial habitats (mean $\pm S D, n=30$ ).

\begin{tabular}{|l|c|c|c|}
\cline { 2 - 4 } \multicolumn{1}{c|}{} & Aquatic habitats & Terrestrial habitats & $P$ \\
\hline Stomatal density (number $\mathbf{~ m m}^{-2}$ ) & $649 \pm 92$ & $319 \pm 65$ & ${ }^{* \star \star}$ \\
\hline Stomatal aperture area $\left(\boldsymbol{\mu m}^{-2}\right)$ & $35.93 \pm 8.86$ & $8.22 \pm 3.68$ & $* \star$ \\
\hline
\end{tabular}

${ }^{* * *} P<0.001$.

As expected, $N$. peltata could acclimate to the terrestrial habitat due to the measurable differences in stomatal and physiologic changes. In agreement with earlier reports (Tsuchiya, 1988), the stomatal density of $N$. peltata significantly decreased under a terrestrial habitat (Figure 5, Table II). Changes in stomatal density in response to water could affect the leaf conductance and water relations of the plant (Woodward et al., 1988; Miyazawa et al., 2006). $N$. peltata could adapt to the terrestrial environment by significantly decreasing its evaporative surface (Tsuchiya, 1988, 1991). Moreover, the present study also found that the stomatal aperture area of $N$. peltata significantly decreased under a terrestrial habitat. These stress avoidance mechanisms are not special per se, but are considerable and extremely effective in this species.

\section{CONCLUSION}

In the present study, we demonstrated that the floating-leaved macrophyte Nymphoides peltata can acclimate well to temporary terrestrial habitats by developing a series 
of photosynthetic acclimation features, which included less stomatal density, smaller stomatal aperture area, lower $E$ and $g_{\mathrm{s}}$, and high WUE. In agreement with previous studies, we believe that floating-leaved plants may play a central role in ecological recovery of lakeside zones, because floating-leaved plants are dominant species in this area and can adapt well to temporary terrestrial and aquatic habitats. These findings may be useful in managing the lakeside zones of shallow eutrophic lakes in the middle and downstream of the Yangtze River, where floating-leaved macrophytes are declining.

\section{ACKNOWLEDGEMENTS}

This research was jointly supported by the National Basic Research Program of China (2012CB417004) and the Major Science and Technology Program for Water Pollution Control and Treatment (2012ZX07101-001).

\section{REFERENCES}

Barko J.W., Adams M.S. and Clesceri N.L., 1986. Environmental factors and their consideration in the management of submersed aquatic vegetation: a review. Journal of Aquatic Plant Management, 24, 1-10.

Calatayud P.A., Llovera E., Bois J.F. and Lamaze T., 2000. Photosynthesis in drought-adapted cassava. Photosynthetica., 38, 97-104.

Engelhardt K.A.M. and Ritchie M.E., 2001. Effects of macrophyte species richness on wetland ecosystem functioning and services. Nature, 411, 687-689.

Estill K., Delaney R.H., Smith W.K. and Ditterline R.L., 1991. Water relations and productivity of alfalfa leaf chlorophyll variants. Crop Science, 31, 1229-1233.

Li Z.Q., Xu J., Cao T., Ni L.Y. and Xie P., 2010. Adaptive response of a floating-leaved macrophyte Nymphoides peltata, to a terrestrial habitat. Journal of Freshwater Ecology, 25, 481-486.

Li Z.Q., Yu D. and Xu J., 2011. Adaptation to water level variation: Responses of a floating-leaved macrophyte Nymphoides peltata to terrestrial habitats. Annales de Limnologie, 47, 97-102.

Luquez V.M., Guiamet J.J. and Montaldi E.R., 1997. Net photosynthetic and transpiration rates in a cholorophyll-deficient isoline of soybean under well-waterd and drought conditions. Photosynthetica, 34, 125-131.

Lynn D.E. and Waldren S., 2003. Survival of Ranunculus repens L. (Creeping Buttercup) in an amphibious habitat. Annals of Botany, 91, 75-84.

Miyazawa S.I., Livingston N.J. and Turpin D.H., 2006. Stomatal development in new leaves is related to the stomatal conductance of mature leaves in poplar (Populus trichocarpa $\times$ P. deltoids). Journal of Experimental Botany, 57, 373-380.

Mommer L., Pons T.L., Wolters-Arts M., Venema J.H. and Visser E.J.W., 2005. Submergence-induced morphological, anatomical, and biochemical responses in a terrestrial species affect gas diffusion resistance and photosynthetic performance. Plant Physiology, 139, 497-508.

Morris C.E., Monier J., and Jacques M., 1997. Methods for observing microbial biofilms directly on leaf surfaces and recovering them for isolation of culturable microorganisms. Applied and Environmental Microbiology, 63, 1570-1576.

Nishihiro J., Nishihiro M.A. and Washitani L., 2006. Assessing the potential for recovery of lakeshore vegetation:species richness of sediment propagule banks. Ecological Research, 21, 436-445.

Picotte J.J., Rosenthal D.M., Rhode J.M. and Cruzan M.B., 2007. Plastic responses to temporal variation in moisture availability: consequences for water use efficiency and plant performance. Oecologia, 153, 821-832.

Robe W.E. and Griffiths H., 1998. Adaptations for an amphibious life: changes in leaf morphology, growth rate, carbon and nitrogen investment, and reproduction during adjustment to emersion by the freshwater macrophyte Littorella uniflora. New Phytologist, 140, 9-23.

Saraswathi S.G. and Paliwal K., 2008. Diurnal and seasonal trends in photosynthetic performance of Dalbergia sissoo Roxb. and Hardwickia binata Roxb. from a semi-arid ecosystem. Photosynthetica, 46, 248-254. 
Tsuchiya T., 1988. Comparative studies on the morphology and leaf life span of floating and emerged leaves of Nymphoides peltata (GMEL.) O. Kuntze. Aquatic Botany, 29, 381-386.

Tsuchiya T., 1991. Leaf life span of floating - leaved plants. Vegetatio, 97, 149-160.

Van der Velde G., Giesen Th. G. and Van der Heijden L., 1979. Structure, biomass and seasonal changes in biomass of Nymphoides peltata (Gmel.) O. Kuntze (Menyanthaceae), a preliminary study. Aquatic Botany, 7, 279-300.

Webb W.L., Newton M. and Starr D., 1974. Carbon dioxide exchange of Alnus rubra. Oecologia, 17, 281-291.

Wells C.L. and Pigliucci M., 2000. Adaptive phenotypic plasticity: the case of heterophylly in aquatic plants. Perspectives in Plant Ecology, Evolution and Systematics, 3, 1-18.

Woodward F.I. and Bazzaz F.A., 1988. The responses of stomatal density to $\mathrm{CO}_{2}$ partial pressure. Journal of Experimental Botany, 39, 1771-1781. 